\title{
EL LIMMITE. SOBRE LA SEGREGACIÓN URBANA EN CONTEXTOS \\ LOCALES
}

\section{The limit. On urban segregation in local contexts}

\author{
Sebastián Aguiar* \\ * Universidad de la República (Uruguay) \\ aguiar.sebastian@gmail.com
}

\section{Palabras clave}

Segregación urbana Justicia local Configuraciones

\section{Keywords}

Urban segregation Local justice Configurations

\begin{abstract}
Resumen
En 1965 N. Elias y J. Scotson realizaron una investigación sobre la localidad inglesa de Winston Parva, que lentamente se ha vuelto clásica. En ese estudio examinan las figuraciones en torno a las fronteras sociales entre quienes residían en un territorio y los llegados posteriormente, a partir del estudio de la sensación de inseguridad provocada por los vecinos más recientes. Desde esa situación buscan aislar una configuración que pudiera extrapolarse en un modelo a otras circunstancias parecidas; en ese ánimo se triangula aquí con otros dos estudios de caso en las localidades de Magdalena, en Manaos (Brasil), y de Valderas, en Montevideo (Uruguay). Los casos estudiados presentan similitudes y ciertas diferencias con Winston Parva, que acumulan en el carácter paradigmático y demuestran la vigencia del análisis de Elias. Pero además, en estos casos, la situación añade un elemento: vecinos organizados construyen una división material entre los grupos - un muro, un portón-. La radicalización respecto a Winston Parva lleva el asunto al límite e invita a profundizar dos discusiones eticopolíticas, subyacentes en el trabajo de Elias y Scotson: los momentos de indecidibilidad y el fundamento místico de la autoridad en esas decisiones, que muestran que la segregación entre nuevos "marginales" y "establecidos" más prósperos es un diferendo que solo provoca víctimas, de distintos tipos.
\end{abstract}

\section{Abstract}

In 1965, N. Elias and J. Scotson carried out a research about the English town of Winston Parva, which has slowly become classical. In that study, they examine figurations on the social borders between those who lived in a territory and those who arrived later, focusing on the insecurity caused by the most recent neighbors. From that situation, they seek to isolate a configuration that could be translate into a model to be used to analyze similar situations. With this aim in view, in this research two other case studies are triangulated, involving the towns of Magdalena, Manaos (Brazil), and Valderas, Montevideo (Uruguay). Both present similarities and certain differences with Winston Parva, which acknowledges the paradigmatic character and the actuality of Elias' work. But the cases analyzed in this research, present an additional element: organized neighbors build a material division between the groups - a wall, a gate- - This radicalization regarding Winston Parva takes the issue to the edge inviting us to deepen into two ethical and political discussions: the moments where talking becomes impossible and the mystical foundation of authority in those decisions. That shows that segregation between new "marginalized" and "established" more prosperous is a dispute that only causes victims, of different types.

Aguiar, S. (2017). El límite. Sobre la segregación urbana en contextos locales. Papeles del CEIC, vol. 2017/2, papel 177, CEIC (Centro de Estudios sobre la Identidad Colectiva), UPV/EHU Press, http://dx.doi.org/10.1387/pceic.17753 


\section{PRESENTACIÓN}

Hace poco más de 50 años que Norbert Elias y John L. Scotson publicaron The established and the outsiders. A sociological enquiry into community problems (2000/1965). El breve libro, al que en sucesivas ediciones Elias fue agregando prefacios e introducciones, no fue exitoso en ese momento: sería valorado unas décadas más tarde cuando el sociólogo alemán ya había adquirido el renombre que hoy lo envuelve. En la actualidad es de seguro un clásico disciplinario, aunque se dispone de contadas traducciones al español ${ }^{1}$. Escrito con lentitud, fue elaborado a lo largo de 5 años durante los que Scotson residió en la localidad inglesa objeto del estudio: Winston Parva (WP). Era profesor allí y los vecinos le solicitaron una investigación, alarmados ante el incremento de la inseguridad en una zona con habitantes que habian llegado en décadas recientes. Él a su vez pidió colaboración a Elias, que trabajaba en la cercana University of Leicester (Reino Unido).

Posiblemente en la delicada descripción, densa pero organizada e intensiva, y en la atención a detalles que casi permiten trasladarse allí, como los rumores o los líderes locales, radica uno de los principales encantos del libro. y en su pretensión "paradigmática", su microsociología que alcanza lo general desde lo particular en busca de aislar los elementos formales, estriba otro de sus hitos. Es probablemente una de las más ambiciosas fundamentaciones de los estudios de caso como herramienta de investigación, comparable a la Presentación de la persona en la vida cotidiana de Erving Goffman (1989). En la localidad, los autores examinan un problema general, buscan "estudiar una figuración universal en una comunidad pequeña, lo que implica la posibilidad de explorar esos problemas con una minucia considerable, microscópicamente, y construir un paradigma empírico" (Elias y Scotson, 2000: 21). Este afán paradigmático, la búsqueda de

\footnotetext{
${ }^{1}$ En España la referencia más relevante es el "Ensayo acerca de las relaciones entre establecidos y forasteros", con una introducción de Jesús Casquete y un comentario sintético pero sustantivo del propio Elias, en la Revista Española de Investigaciones Sociológicas (2003). Este comentario también se incluye como un capítulo en La sociedad de los padres y otros ensayos (Elias, 1998), con el nombre "Ensayo teórico sobre las relaciones entre establecidos y marginales". Existe una reciente edición del trabajo completo en México del Fondo de Cultura Económica (2016), con el título Establecidos y marginados. Una investigación sociológica sobre problemas comunitarios. Aquí se referencia, excepto cuando se indica específicamente, la edición en portugués, la más difundida en nuestra región: Os estabelecidos e os outsiders: sociologia das relações de poder a partir de uma pequena comunidade (2000).
} 
"estructuras constantes", es particularmente subrayado en los comentarios a las ediciones del libro que escribió Elias posteriormente, como el posfacio a la edición alemana (ibídem: 199 y ss.).

En esa consigna se inscribe lo que sigue. Se presentarán otros dos estudios de caso, en las pequeñas localidades de Magdalena, en las afueras de la ciudad de Manaos (Brasil), y de Valderas, en la periferia de Montevideo (Uruguay)" que acumulan en la dirección de ese "carácter paradigmático" de las disputas de poder en el territorio. Es que el problema que aborda Elias es de plena vigencia, si cabe aún más radical, en la actualidad. Son innumerables los ejemplos, variados en sus contenidos pero análogos en sus formas, de segregación localizada. Esos procesos de limitación pueden tener menor o mayor trascendencia, pero suelen ser situaciones intensas para los participantes. Y los mecanismos localizados en WP, de efectivamente haber sido paradigmáticos, deberian aportar a la comprensión de lo que pueda hallarse de similar y también invitar a la interpretación de las diferencias que aparezcan ${ }^{3}$.

El libro es un estudio seminal, también, como atestado de esos trabajos de síntesis que caracterizaron las tres décadas que siguieron a la mitad de siglo pasado, que buscaban amalgamar autores clásicos y elaborar esquemas conceptuales que articularan la herencia sociológica. Elias lo logra mejor que casi todos, con una aplicación ejemplar, comparable a La ética protestante y el espíritu del capitalismo (Weber, 2004), breve y conciso pero absolutamente original y de enorme potencial interpretativo. El paralelismo entre ambos autores se sostiene también en su apuesta comprensiva, que parte del sentido mentado y se cimenta en mecanismos interpretativos similares. Además, Elias y Scotson tienen su centro de atención en el poder y lo abordan, más tácita que explícitamente, desde la acción social a la Weber. Es evidente la presencia de Émile Durkheim, en el foco en la anomia, en las normas sociales, en la solidaridad, en el modo de argumentar en ocasiones, con

\footnotetext{
${ }^{2}$ Como en el trabajo de Elias y Scotson, los nombres de las localidades son ficticios.

${ }^{3}$ Este trabajo fue presentado como ponencia en la Reunión de Antropología del Mercosur en diciembre de 2015, donde rápidamente surgieron varios ejemplos similares en la región que funcionaban en forma idéntica. También fue presentado en la ciudad de Paysandú (Uruguay) en junio de 2016, donde en un barrio de la periferia de la ciudad se instalaron nuevos vecinos que los anteriores resistieron, al punto de que el jefe municipal fue apuñalado en una reunión. La apuesta del artículo, en sintonía con la de Elias, es que presente rendimiento heurístico para distintas situaciones, escalas y contextos.
} 
tablas de frecuencias y mostrando comparaciones de tasas y frecuencias medias. Pero no cabe duda de que el objeto, el problema, es típicamente simmeliano, centrado en la interacción social, en un análisis formal del establecimiento de límites y su "incomparable firmeza". En WP, Elias se acerca a la relación entre establecidos y outsiders o marginales: la erección de fronteras, la segregación urbana en el sentido más formal del término. Efectivamente, la noción de frontera es colocada en el espacio del análisis sociológico por Georg Simmel, con quien trasciende el nivel meramente geográfico; son conocidos también los enfoques posteriores en antropología de Fredrik Barth (1976), los desarrollos hacia la teoría de sistemas, en particular de Niklas Luhmann (1998) o la propuesta de "fronteras simbólicas" (Lamont y Fournier, 1992). Todos ellos coincidirían con Elias y Scotson en que:

\begin{abstract}
"el problema es saber cómo y por qué los individuos se perciben unos a otros como pertenecientes a un mismo grupo y se incluyen mutuamente dentro de las fronteras grupales que establecen al decir 'nosotros', mientras que, al mismo tiempo, excluyen a otros seres humanos a quienes perciben como pertenecientes a otro grupo y a quien se refieren colectivamente como 'ellos' (2000: 38).
\end{abstract}

La palabra establecidos se utiliza en inglés para grupos o individuos que tienen una posición de prestigio y poder, a partir de una combinación singular de tradición, autoridad e influencia. Se asocia a la acepción en español, que el Diccionario de la Lengua Española (RAE, ASALE) remite a 'orden establecido' y define como 'organización social, política, económica, ideológica, etc., vigente en una colectividad'. Por su parte, los outsiders son quienes quedan fuera de esos códigos establecidos, marginales: 'dicho de una persona o de un grupo: que vive o actúa, de modo voluntario o forzoso, fuera de las normas sociales comúnmente admitidas'. En este marco, Elías destaca "la semejanza del patrón de estigmatización usado por los grupos de poder elevado en relación con sus grupos outsiders en el mundo entero a despecho de todas las diferencias culturales" (ibídem: 128).

Los estudios de caso que se presentan aquí, además de un homenaje y de probar cómo iluminan las figuras encontradas en WP las situaciones de segregación aún en la actualidad, incorporan algunos matices específicos de particular interés para el establecimiento de límites en sociedades poscomunitarias. Son situaciones de segregación espacial en las que tiene lugar un suplemento: se construye un límite físico -un 
muro, un portón- que divide materialmente los dos grupos. Esta radicalización lleva al límite, extrema también, una pregunta, por así decirle, "eticopolítica" que subyace al trabajo de Elias y Scotson, acerca de la justicia en estas situaciones. Se consideran en el último apartado varios autores que aportan a esta pregunta de fondo, particularmente las reflexiones de Jacques Derrida (2008) sobre la indecidibilidad y el fundamento místico de la autoridad. Así se evidencia el diferendo subyacente, sus víctimas y se esbozan algunos comentarios liminares en torno a la hospitalidad en ese ánimo eticopolítico.

A continuación se presentan las tres situaciones, los estudios de caso que conforman la base empírica. Primero, se introduce brevemente a la situación en WP y la investigación que realizaron Elias y Scotson. El trabajo de campo propio fue realizado por una parte en Magdalena, en la periferia de Manaos ${ }^{4}$, y por otra parte en Valderas, en Parque Lisboa, una localidad de las afueras de Montevideo ${ }^{5}$.

\subsection{Wiston Parva}

Winston Parva es una pequeña ciudad en el sureste de Inglaterra, en las afueras de Leicester, donde en los años 50 residian alrededor de 5000 habitantes. De economía mayormente fabril, se componía en ese momento por tres "zonas": una central (la "aldea"), otra residencial, donde habitaban los más poderosos entre los aldeanos, y una tercera compuesta por un conjunto más heterogéneo de loteamientos recientes. Scotson fue profesor allí durante varios años, y el consejo vecinal le solicitó un análisis sobre la concentración de la delincuencia en esa tercera zona. Con Elias como supervisor, realizaron durante cinco años una investigación cuyo objeto central fue variando desde la inseguridad hasta las figuraciones articuladas en torno a las relaciones formales de segregación.

La zona 3, consolidada más recientemente tras oleadas inmigratorias debidas a la Segunda Guerra Mundial y a realojamientos derivados de

\footnotetext{
${ }^{4}$ En 2012 residí allí, realicé varias entrevistas en la zona en un marco etnográfico, y participé de reuniones barriales y del grupo de correos de los vecinos, que se analiza en el trabajo. Fueron cerca de 400 correos, en el período febrero de 2010 a abril de 2011. El grupo incluía 180 direcciones.

${ }^{5}$ En el marco de una investigación coordinada por la Dra. Verónica Filardo, nos encontramos en 2007 con un problema entre vecinos, en un territorio donde la Intendencia de Montevideo (IM) estaba proyectando una intervención de regularización urbana. Organizamos alli dos grupos de discusión y una decena de entrevistas.
} 
políticas de vivienda, era señalada como foco del problema; algunas familias tenían un comportamiento problemático pero, aunque la situación fue mejorando en términos objetivos a lo largo del desarrollo de la investigación - con una equiparación de las tasas de participación en crímenes en las tres áreas-, los vecinos seguían siendo "estigmatizados por la delincuencia, la violencia y la desintegración" (Elias y Scotson, 2000: 38). Los habitantes de esta zona, por su parte, no percibían a los antiguos moradores como distintos de ellos.

\begin{abstract}
"Intentaron establecer contacto con algunos pero fueron rechazados. Fue así que se concientizaron de que los antiguos residentes se percibían como un grupo cerrado, al que se referían como 'nosotros' y percibian a los nuevos como un grupo de intrusos, a quien se referían como 'ellos' y que pretendian mantener a distancia" (Elias y Scotson, 2000: 38).
\end{abstract}

Por su parte, la población establecida en WP, de las zonas 1 y 2 , "se conocía hace más de una generación y habían establecido un estilo de vida común y un conjunto de normas. El flujo de recién llegados a su barrio era sentido como una amenaza a su forma de vida establecida" (ibídem: 25). En WP no había fuertes diferencias desde el punto de vista laboral o de los indicadores sociológicos corrientes (ingresos, diferencias raciales o educación); más bien los establecidos fundaban su autoridad en un principio de antigüedad: vivían allí antes que los otros.

\title{
1.2. Magdalena
}

El conjunto residencial Magdalena, en el este de Manaos, fue fundado en 1981 como una cooperativa de vivienda para funcionarios de una institución pública. Es un barrio reciente pero tampoco nuevo: la capital de Amazonas crece con velocidad. Se trata de un gran predio con enormes áreas verdes, de 226 viviendas extendidas en $500.000 \mathrm{~m}^{2}$. En su inauguración, el diario de la asociación de funcionarios señalaba que era un sueño hecho realidad. Las construcciones han variado en estos 35 años: algunas son lujosas, otras mantienen los diseños originales, la mayoría de los dueños ha cambiado y quedan ya pocos funcionarios. El estatuto legal del conjunto está a medio camino entre un barrio abierto y un condominio: se encuentra rodeado por un perímetro y cuenta con casetas con guardias de seguridad privados, pero los servicios de limpieza y policía son municipales. 
En los años 90 se consolidó el asentamiento de Vila Argento, lindero al este de Magdalena, tras la invasión y el loteo informal de una gran propiedad. Sus habitantes provienen en general de los estados del empobrecido norte brasileño o de poblados en el Amazonas. Como todas esas apropiaciones que multiplicaron el tamaño de la ciudad en el periodo, pronto fue legitimada oficialmente, logrando un relativamente rápido aumento de la prosperidad, aun manteniendo algunos bolsones marginales.

En los años siguientes se incrementó la sensación de inseguridad en Magdalena y se organizó una agrupación de vecinos. Tras su fundación, el barrio había intentado mantener el espíritu cooperativo y cierta organización, pero la venta de propiedades debilitó la comunidad y denuncias respecto al pago de prestaciones sociales por parte de los guardias de seguridad que vigilaban las dos rutas de acceso liquidaron financieramente la asociación, que hubo de disolverse en términos formales para no asumir la deuda. En la actualidad, en la conversación entre los vecinos aparecen nuevamente numerosos diagnósticos de una fuerte sensación de inseguridad. Como en WP, esa será la plataforma de la inquietud también en este caso: "La seguridad en Magdalena es lamentable, está empeorando. Hace ya un tiempo que vienen ocurriendo asaltos", me advertía un entrevistado que vivía hacía tiempo, en mis primeros días allí.

\subsection{Valderas}

Parque Lisboa, en el noreste de Montevideo, es una localidad empobrecida en la periferia noreste de Montevideo. Su urbanización comenzó en 1909 y desde los años 70 se ha consolidado su posición periférica en el cinturón urbano. Se han formado varias zonas, vecindarios, que las personas sienten y utilizan como sus barrios, aunque no coincidan con límites administrativos. Una de ellas es Valderas, en torno a la calle de ese nombre, de construcciones humildes pero sólidas y con vecinos que en su mayoría viven allí hace varias décadas. Hacia los fondos, tras la paralela calle 7 había un descampado inundable al que se podía cruzar por un callejón que cortaba las largas manzanas del barrio. En los años 80 allí solo residían algunas familias. Progresivamente esa zona se fue habitando en forma irregular y en la primera década del 2000 la calle 7 pasó a estar densamente poblada. Se arraigaron dos zonas 
separadas, barrios en sí mismos: "Como que Valderas es un barrio y Calle 7 es otro", dicen ellos; "es otro mundo de acá para abajo".

Desde que a finales de los años 80 comenzara a construirse el asentamiento irregular en el descampado, los habitantes de Valderas reconocen que hubo barreras entre ambas zonas. Esta distancia se incrementó cuando en el año 2002 se edificó un conjunto de viviendas donde se realojó a familias que ocupaban un hipódromo abandonado, que fue refaccionado. Se consolidó entonces la zona de la Calle 7 , con vecinos más heterogéneos y humildes. Se estableció así una diferencia de "los arriba" y "los de abajo", y los nuevos vecinos son vistos con hostilidad: "conventillo" le dicen los más mayores, "cante", los adultos y jóvenes, a la zona.

Las diferencias entre los vecinos no son económicas, sino en clave de antigüedad y de integración social: aquí la línea divisoria tiene lugar entre "humildes integrados" y "excluidos o marginales", que no necesariamente son más pobres en términos de ingresos. La intensidad con que se ha internalizado la violencia es alta: los robos son frecuentes, se percibe invasión y apropiación de espacios y el uso de armas adquiere una generalización alarmante, "los conflictos se arreglan a los tiros". No hay recursos a los que acudir, los enfrentamientos deben resolverse entre los protagonistas y comienza a reunirse una comisión de vecinos de Valderas, con este problema como uno de sus temas fundamentales.

\section{LA CONFIGURACIÓN}

Los tres casos presentan entonces varios aspectos en común. En los tres el detonante de la segregación es la sensación de inseguridad en los establecidos respecto a los outsiders, quienes llegaron después pero también presentan un estatus inferior y son más heterogéneos. En lo que sigue, se busca aplicar a esas situaciones contemporáneas el esquema analítico propuesto por Elias y Scotson. Que el potencial interpretativo del texto permaneciera, que nos hablara con pertinencia, era precisamente su pretensión: un estudio de caso microsociológico, en profundidad, que permitiese establecer un modelo general, paradigmático, para estos procesos de establecimiento de fronteras.

"Concentrada en la forma de un modelo, la configuración encontrada en miniatura en WP muestra con claridad sus implicaciones para un campo más amplio. No se trata de elogiar ni de censurar, sino de contribuir para una mejor 
comprensión y explicación de las interdependencias que, en esa comunidad, atraparon a dos grupos en la trampa de una configuración que no crearon pero que produjo tensiones y conflictos específicos entre ellas" (Elias y Scotson, 2000: 172).

La noción de configuración es central a lo largo de la obra de Elias. En sus trabajos más conocidos es utilizada en un sentido amplio, como cuando analiza la sociedad cortesana, refiriéndose a conjuntos sociales y a formaciones epocales, macrosociológicas:

"Procesos sociales que implican complejos vínculos de interdependencia entre las personas, que no son estructuras externas o coercitivas que accionan, sino una serie de lazos largos y diferenciados, que se desarrollan a través del tiempo, que superan la perspectiva del individuo 'clausus'" (1989: 45).

Pero la definición también habilita un abordaje microsociológico, que aparece con claridad en Establecidos y outsiders. En esta línea interpretativa, el concepto de configuración presenta un aire de familia con el análisis de mecanismos sociales, que remite a Jon Elster (1999, 2005; también incluso a Robert Merton, 2003). Como las configuraciones son encadenamientos más generales que los fenómenos y que permiten explicarlos, que superan la descripción concreta y que, sin llegar tampoco a proponerse como aplicaciones universales, pueden ser encontrados en contextos variados y servir de modelo a otros casos aún no encontrados. Elias quizá no coincidiese con Elster en su basamento en el individualismo metodológico ni en el énfasis en la acción racional ${ }^{6}$, y utilizó solo ocasionalmente la noción de mecanismo, pero efectivamente busca desmontar una caja negra, encontrar engranajes que componen y explican un funcionamiento. $y$, claramente, su investigación en WP es propuesta por Elias como un estudio paradigmático: "un modelo explicativo, que permite comprender las características estructurales y las razones por las que en condiciones diferentes, funcionan y se desarrollan siguiendo diferentes líneas" (Elias y Scotson, 2000: 21). Cuatro factores, engranajes, correspondientes a los capítulos de Establecidos y outsiders aparecen como fundamentales en este mecanismo o configuración.

\footnotetext{
6 "El ideal de la racionalidad en la conducción de las cuestiones continúa a barrar el acceso a la estructura y la dinámica de las figuraciones establecidos/outsiders, como también las fantasías grupales de grandeza que suscitan, y que son datos sociales sui generis, ni irracionales ni racionales." (Elias y Scotson, 2000: 37).
} 


\title{
2.1. Cohesión interna
}

En primer lugar, para la interpretación del entramado de interacción, Elias apunta que:

\begin{abstract}
"los grados de cohesión interna y de control comunitario desempeñan un papel decisivo en la relación de fuerzas (...). Por su mayor grado de cohesión, así como la activación de este por el control social, los antiguos residentes conseguian reservar los cargos importantes de las organizaciones sociales" (Elias y Scotson, 2000: 22).
\end{abstract}

En los tres casos hay una relativamente fuerte vinculación interna entre los establecidos, quienes marcan el límite, un "nosotros", al que se atribuyen buenos principios y seguimiento de las normas acordadas (bañarse en el lago o respeto por las áreas verdes de Magdalena, el uso del cine en WP, el respeto a los vecinos en Valderas). Y en los tres casos, en este marco, hay organizaciones legítimas que agrupan a los establecidos y defienden sus intereses; frente a ellos, los vecinos "outsiders" son claramente más heterogéneos y desorganizados.

En Magdalena, el grupo de correos se convierte en un espacio de administración comunitaria cotidiano. Es también el principal lugar de convocatoria de las reuniones presenciales, las asambleas, que a su vez serían el espacio decisor en el "conjunto", como llaman a su barrio. Algunas de las voces, en torno a diez, son las más activas y lideran la conversación. Otras aparecen con menos frecuencia y un importante número son intervenciones puntuales. Por su parte, los vecinos de Valderas están organizados en una comisión que agrupa a la mayoría de los habitantes antiguos, que comenzó a reunirse por los problemas de inseguridad en el barrio. A su vez, en el barrio existe un concejo local, donde esos vecinos tienen un representante municipal.

En WP, Elias y Scotson describen expresivamente al principal referente local, el consejero Drew, un próspero empresario de la construcción, representante del condado y miembro del consejo distrital urbano. Independiente políticamente, aunque cercano al partido conservador, mayoritario en WP pero minoritario en la zona 3, se postulaba en forma autónoma y elección tras elección obtenía un amplio apoyo en las zonas 1 y 2. En Magdalena, una bióloga, Érika, fungía a la vez como principal moderadora en el foro de correos, realizaba los resúmenes y órdenes del día de las asambleas y contaba con el apoyo del núcleo de vecinos más activos, con cierta autonomía operativa más tácita que explícita. Fue 
elegida representante para los trámites del barrio y sostenía una línea argumental ambientalista que se había convertido en recurrente motivo de orgullo en las autoidentificaciones colectivas. Por su parte, el más ilustre habitante de Magdalena, el pintor y artista Paulo Costa, operaba como un líder informal, casi simbólico. Es tras un mediático asalto a su casa cuando se cataliza la discusión sobre la inseguridad en el barrio, los vecinos participan más masivamente en las asambleas y se refuerza el sentimiento local. Sus opiniones eran escuchadas y repetidas luego por los vecinos. Por su parte, en Valderas, Luis Jorge es claramente el representante político, con una clara trayectoria militante en un sector político del partido de gobierno, contactos en la Intendencia y electo como delegado al concejo municipal. Por su parte, Washington es un líder, por así llamarlo, moral. Pastor evangelista, lleva adelante en su casa un merendero para niños del barrio, mayormente de la Calle 7, donde también realizan actividades de apoyo escolar que representan un recurrente motivo de orgullo en Valderas. En su terreno se reúne la comisión vecinal. Estas organizaciones y líderes adquieren en todos los casos gran importancia en las relaciones comunitarias. Abogan con legitimidad por las causas grupales y se presentan como ejecutores de la gestión de los asuntos barriales, y en ello de un derecho, de una autoridad colectiva.

\subsection{Identificaciones pars pro toto}

En segundo lugar, "no es fácil entender la mecánica de la estigmatización sin un examen del papel desempeñado por la imagen que cada persona hace de la posición de su grupo entre otros" (Elias y Scotson, 2000: 25). Por una parte, los grupos más poderosos, en todos los casos, se ven a sí mismos como personas mejores, dotadas de una virtud específica, compartida por todos sus miembros y que falta en los otros (ibídem: 20). En WP, Valderas o Magdalena los superiores se enorgullecen por ejemplo de ser "más limpios" (ibídem: 28). La propia capacidad de organizarse y el respeto a ciertos códigos aparecen como características definitorias de la identidad autoatribuida como "moralmente superior" en los tres casos. En Valderas, el merendero regenteado por Washington y varias anécdotas de ayuda a vecinos en ocasión de inundaciones, por ejemplo, evidencian una moral que caracteriza a los establecidos y que falta en Calle 7, donde "no se ayudan entre ellos". En Magdalena, el respeto a la naturaleza y la solidaridad interna ante robos o accidentes caracteriza al "nosotros" ante la 
suciedad de los vecinos. Por oposición, los outsiders son, en los tres casos, calificados como desordenados, sucios, peligrosos e, incluso, en las tres ciudades, literalmente como "feos", pese a no haber diferencias de apariencia ${ }^{7}$.

Elias sintetiza estas referencias denominándolas argumentos pars pro toto, simultáneamente defensivos y agresivos: la formación de la imagen de los grupos outsiders en términos de su minoría anómica y la formación de la imagen de los establecidos con base en la conducta y el modo de ser de sus mejores miembros.

\begin{abstract}
"Un ejemplo de las constantes estructurales en las relaciones entre establecidos y outsiders: el grupo establecido tiende a atribuir al conjunto del grupo outsiders las características 'ruines' de su porción 'peor'. En contraste, la autoimagen del grupo establecido tiende a modelarse en su sector ejemplar, la minoría de sus 'mejores' miembros. Esa distorsión faculta al grupo establecido probar sus afirmaciones a sí mismos y a los otros" (íbidem: 22).
\end{abstract}

Estos argumentos pars pro toto aparecen en forma recurrente tanto en Magdalena como en Valderas. Cuando la situación se tematiza, la explicación es casi idéntica: "Claro que existen personas de bien del otro lado, pero no son esas personas las que están destruyendo todo", señalan por ejemplo los primeros. Y en Valderas también se reconoce que en Calle 7 la mayoría de las personas no son delincuentes: "No miro con malos ojos al $80 \%$ de los vecinos buenos, miro con un poco de resabio al $20 \%$ que me parece malo, y tiene más peso el $20 \%$ o el $5 \%$ de los malos que el 95 \% que es bueno, [que] tiene mucho más peso".

En Valderas se da además el agregado de que sus habitantes padecen ese mismo tipo de estigmatización. Denuncian que son señalados en forma generalizada en la ciudad, que desconsidera y estigmatiza el barrio Parque Lisboa y en ello Valderas, pero a su vez repiten el mismo mecanismo generalizador:

\footnotetext{
${ }^{7}$ En WP Elias lista una serie de calificaciones de "ellos" que realizan los establecidos. La enumeración no busca ser exhaustiva o sentar una tipología, pero todas ellas se repiten en forma textual en Valderas y Magdalena, lo que no deja de ser expresivo (Elias y Scotson, 2000: 112-113). Una cuestión de códigos: "no tienen los mismos códigos que nosotros"; culturas diferentes: "son gente de otra clase"; ellos son conflictivos: "siempre están peleando"; depende de dónde vienen: "salidos de las favelas/cantes/cockneys"; una cuestión de crianza: "no tienen autoridad sobre los hijos".
} 
-[En Montevideo] hablan de Parque Lisboa como... Todo así... Como si fuera todo lo mismo... Todo un cante gigante.

-Aparte también nosotros encerramos al cante como si toda la gente fuera mala y en el cante tampoco son toda gente mala.

-Hay gente buena, pero lo que pasa que ta... Hay de todo...

-Es gente marginada.

\subsection{Rumores, historias y anécdotas}

Elias presta también particular atención a las palabras despreciativas, imágenes con las que son investidos los grupos segregados, que inflan retóricamente la segregación: "Con frecuencia los propios nombres de los grupos que están en una situación de outsiders traen en sí, hasta incluso para los oídos de sus miembros, implicancias de inferioridad y deshonra" (Elias y Scotson, 2000: 27). Así sucede con "el cante", calificativo que, asociado con una actitud, se dirige a los habitantes de Calle 7, para quienes también tiene implicancias. De hecho, ellos usan esa misma palabra para referirse a quienes en el asentamiento presentan actitudes más conflictivas:

"La mayoría de las personas dispone de una gama de términos
que estigmatizan a otros grupos, y que solo hacen sentido en
el contexto de relaciones especificas entre establecidos y
outsiders. (...) Todos esos términos simbolizan el hecho de que
es posible avergonzar al miembro de un grupo outsider por no
estar a la altura de las normas del grupo superior" (ibidem:
27 ).

Como vehículo de estas imágenes y sinécdoques, Elias destaca la importancia del rumor despreciativo (blame gossip), indisociable del elogioso (pride gossip), que suele referirse al propio individuo o al grupo con el que se identifica. Así, en WP, el nivel organizacional relativamente alto de la aldea facilitaba la transmisión de los rumores boca a boca y permitía que las noticias se esparcieran por la comunidad con una velocidad considerable. La situación es similar, aunque con algunas variaciones, en las otras dos localidades. En Valderas también opera el rumor y predomina la circulación de experiencias propias y ajenas de inseguridad en el barrio que se decían causadas por los vecinos de Calle 7:

- Como que hay una diferencia entre la gente que ya era de acá... 
-Quizás los que ya eran de acá saben que no da para andar robando en el barrio y capaz que los que vienen de otro lado, como no conocen a la gente...

-No saben quién sos

-Para ellos sos una persona más.

Las anécdotas son cercanas, muchos han sido tocados por pequeños robos y conocen de los que han sido objeto los demás. En los grupos de discusión era recurrente la enumeración, realizada para el investigador, de una serie de casos que todos conocían.

En Magdalena, en el foro grupal se narran numerosas anécdotas que contribuyen a consolidar el señalamiento a Vila Argento. En particular historias de robos, pero también otras, como cuando se enumera detalladamente la basura que dejan en los lugares donde se reúnen.

"La estigmatización de los outsiders exhibe algunos trazos comunes en una vasta gama de configuraciones de establecidos/outsiders. La anomia tal vez sea la censura más frecuente: repetidamente se constata que los outsiders son vistos por el grupo establecido como indignos de confianza, indisciplinados y desordenados" (ibídem: 27).

En el período de debate en el grupo de correos que se analiza, 14 meses, se relatan en torno a una decena de asaltos a casas. La mayoría requiere un despliegue organizativo importante, más propio de organizaciones criminales, pero en varios de los correos se apunta a grupos de jóvenes y adolescentes del barrio de al lado como los probables responsables.

Tengo visto un grupo de 5 o 6 chiquillos, adolescentes y niños que no viven aqui, "passeando" por la calle, utilizando los paseos, y mi secretaria me informó que tienen la costubre de visitar a vecinos que viven cerca del lago. No estoy queriendo decir que sean ellos, pero por las circunstancias es bien probable.

\subsection{Jóvenes marginales}

Elias y Scotson dedican el último capítulo a los principales causantes de la sensación de inseguridad: los jóvenes de la zona 3. Primero muestran que efectivamente hay una diferencia en la delincuencia juvenil entre las zonas y que la mayoría de los que tuvieron problemas con la policía en el período provenían del loteamiento. Luego, con el ánimo comprensivo que caracteriza el texto, evidencian varias explicaciones de 
la situación, algunas derivadas de la mayor consolidación comunitaria de la aldea: por ejemplo, apuntan que las oportunidades de crianza satisfactoria fueron muy diferentes; o también que en la aldea los jóvenes integran colectivos más sólidos que operan como un "refuerzo de la comunidad" y dificultan la trasgresión; así como la transmisión intergeneracional de incentivos; procesos que redundan en un modo distinto de vivir, de proyectarse:

"Los jóvenes en otros medios sociales pronto aprenden a pensar en términos de futuro. Para la mayoría de los jóvenes indisciplinados del loteamiento era difícil tener cualquier visión de sí mismos a largo plazo. Vivían en el presente y para el presente. Esa era otra diferencia, que contribuía a erigir barreras con los demás" (Elias y Scotson, 2000: 144).

En este marco, Elias describe varias situaciones concretas, como una pandilla de jóvenes con varias entradas y salidas de la comisaría, que se movían en la noche por la zona 2, con conductas transgresoras, violentas y que eran objeto de rumores y anécdotas.

En Magdalena, entre los sujetos causantes de inseguridad, también predominan las referencias a jóvenes, niños y adolescentes.

Siempre veo grupos de chiquillos o adolescentes que no son vecinos caminando por Magdalena. El viernes pasado vi dos muchachos bien jóvenes, uno de ellos con un brazo entablillado. Avisé a la seguridad y le pedí que interviniese con esos niños.

La principal referencia para los sujetos que causan miedo son los jóvenes "marginales", que vienen de fuera. Es una nomenclatura que genera discusiones en el foro, pero que tras un debate se acepta "adecuada": "Lamentablemente, 'guerra' y 'marginales' son las palabras más adecuadas para esta situación".

En Valderas se cuentan historias tremendas de jóvenes incorregibles, de enorme violencia, marcadas por la droga. Varios han sido detenidos por la policía, pero salen rápido y vuelven al barrio:

- Los que se destacan más están todos presos. (Silencio).

-Ahora, cuando salgan, vas a ver lo que es eso...

-En realidad, entran y salen.

Lo interpretan como una cuestión de principios, de mentalidad: "se crían en ese ambiente". 
Por su parte, los jóvenes señalados, por ejemplo Pedro, de 22 años, que vivió en Calle 7 y ha cometido varios delitos desde que era niño, cuando falleció su padre, denuncia que se los juzga sin conocerlos: "Sin conocerlas ni acercarte no podés juzgar a las personas. El que habla y no se acerca a las personas y no las conoce, ese es un antisocial". Y explica:

La gente que vive en los cantegriles es muy pobre. No es lindo, viviendo en un rancho de lata, sin nada para comer. Y, claro, algunos salen a robar, como también podés encontrar gente buena, humilde. Mucha gente sale a requechar en un carro y van a la feria, y pienso que eso debe ser indignante para una persona. Laburar todo el día juntando basura y no tener para comer, para darle cosas a tus hijos (...) Sentís el desprecio en la mirada, en cómo te hablan. Y eso es feo. Te da rabia. Somos todos seres humanos (...) Algunas veces pienso eso, hay gente que gana miles de pesos, mucha plata, y gente que no tiene un pedazo de pan. No te da muchas oportunidades la sociedad esta. Yo, por ejemplo, muchas veces estuve buscando trabajo, fui a muchos lugares. Y no me llamaban de ningún lado. Quedás afuera.

\section{JUSTICIA Y VÍCTIMAS}

En los tres casos la relación de antecedencia detona un imaginario atribuido a "ellos", que en forma relacional define un "nosotros", con la aplicación de argumentos pars pro toto que generalizan para unos los aspectos de la minoría peor y para otros los de la minoría mejor. Actúan líderes y organizaciones consolidadas de una parte y aparece mayor heterogeneidad entre los habitantes de la otra. Circulan en soportes diversos anécdotas y rumores muy parecidos en los tres casos, que consolidan esas calificaciones, historias ciertas, importantes, que de cualquier modo apuntan solo a unas pocas familias. En este marco, el señalamiento generalizado se dirige en todos los casos a determinados "jóvenes marginales".

En torno a estos engranajes, las diferencias, similitudes, características específicas, son relevantes para comprender cómo la configuración tiene lugar en cada caso, cuáles han sido las condiciones sociales que permiten o han construido esa frontera simbólica (Álvarez-Rivadulla, 2017). Así, los liderazgos específicos, los rumores concretos, la calificaciones, etc., permiten analizar cómo se plasma la configuración y se aterriza en las distintas situaciones. 
Pero el carácter paradigmático, comprender la configuración, no solo permite visualizar parámetros relevantes, producto de la equivalencia formal, u ordenar las descripciones específicas de otras situaciones: también invita a interpretar el efecto de variables que se modifican en uno u otro caso. En los aquí considerados existen varias diferencias, cuatro de ellas particularmente relevantes. En primer lugar, es evidente la distancia temporal: entre el análisis de Elias de WP y los eventos en Magdalena y Valderas transcurrieron casi 50 años. Numerosos aspectos concretos muestran este hecho: el uso del grupo de correos virtual es el más claro. Otra diferencia central es el incremento de los niveles de violencia. En WP había peleas, algunos robos y problemas con la policía, que alimentaban un malestar genuino pero diferente al que puede encontrarse en Magdalena y fundamentalmente en Valderas, donde la violencia alcanza otra intensidad: en el primer caso se denuncian copamientos y asaltos a casas; en el segundo robos, tiroteos y trayectorias criminales. En tercer lugar, también hay una diferencia en las situaciones económicas en cada uno de los casos: a grandes rasgos, en Winston Parva la clase media trabajadora se enfrenta a personas de una posición económica similar pero algo inferior, como también en Valderas, aunque aquí las posiciones económicas son bajas y muy bajas. En Magdalena las cosas suceden entre posiciones medias superiores con medias inferiores. Estas tres primeras variaciones, todas ellas relevantes, muestran la resistencia del modelo: se mantiene invariable, constante en sus engranajes centrales pese al lapso transcurrido, el incremento de los niveles de violencia y los cambios en las relaciones económicas entre las partes. Pero, en particular, y en cuarto lugar, otra variación entre los casos presenta potencial heurístico: la materialización del límite, el establecimiento de una división, la cristalización de la frontera social en una física. Con unos portones que se cierran durante la noche los vecinos de Valderas obstruyeron el acceso directo a Calle 7; los vecinos de Magdalena deciden en su foro virtual erigir un muro que los aísle de Vila Argento y lo construyen.

La radicalización en estas situaciones permite profundizar en una pregunta central pero subyacente en el análisis sobre WP. Elias apunta, como se citaba arriba, que "no se trata de elogiar ni de censurar, sino de contribuir para una mejor comprensión" (Elias y Scotson, 2000: 172) —en una evidente referencia a Simmel (2005) - , que cierra su trabajo más conocido sobre la ciudad concluyendo que "no es nuestra tarea la de 
acusar o perdonar, sino solo la de entender". Es que su lógica analítica "formal" implica que la toma de postura suele ser suplementaria: la articulación de los engranajes implica un enfrentamiento de intencionalidades que los actores suelen poder explicar, y en las disputas entre grupos es extremadamente difícil distinguir entre el "conflicto real" y el "simple prejuicio" ${ }^{8}$. Sin embargo, la cuestión de la justicia en WP insiste en su trabajo, aunque sea en forma más tácita que explícita, y finalmente Elias y Scotson proponen que "Ios síntomas de inferioridad humana con que los grupos establecidos suelen identificar a los outsiders de bajo poder, y que sirven a sus miembros como prueba de su valor superior, acostumbran a ser generados por las propias condiciones de la posición de outsiders" (ibídem: 28). Esto es, defienden que los segregados están expuestos a una situación más bien injusta.

En WP, en los tres casos, quienes habían llegado no tenían la sensación de conformar un grupo hasta que fueron segregados. Eran vecinos heterogéneos, algunas familias habian criado niños en contextos de carencias y escasez de oportunidades, y Elías y Scotson afirman que es preciso comprenderlos. Es una decisión adecuada, pero puede mantenerse por unas páginas en suspenso. La diferencia que implica el suplemento de la barrera física invita a reflexionar, finalmente, en un ánimo de algún modo deconstructivo, sobre "la ausencia de límite seguro" (Derrida, 2008: 13).

\subsection{El muro de Magdalena}

Frente a la violencia, los asaltos y el deterioro de los espacios verdes, los vecinos organizados de Magdalena decidieron en 2012 levantar un muro que cerrara el complejo en el límite con Vila Argento. La posibilidad había estado presente en discusiones durante años anteriores, pero una sucesión de robos volvió a colocarla en el tapete. Impactó particularmente el asalto a la residencia del artista Paulo Costa, objeto de una importante cobertura en la televisión y la prensa. Dos de los responsables fueron asesinados durante la larga persecución policial y los otros dos atrapados a las semanas. En ese marco, se convocó a una asamblea frente a la casa de Costa. "¡La reunión fue un éxito! Estuvieron presentes más de 40 moradores". Con este empuje empieza la

\footnotetext{
${ }^{8}$ Como señala Gordon Allport: "el conflicto real es como una nota en un órgano. Provoca la vibración simultánea de todos los prejuicios armónicos. Al oyente le resulta difícil distinguir la nota pura entre la espesura de sonidos" (1962: 260).
} 
construcción y una colecta. "Son un total de 120 metros de muro. Comenzaremos por donde los accesos de personas extrañas están predominando. El muro tendrá tres metros de altura, dos cintas de concreto y piedras, y un metro de cimiento".

Algún vecino imagina la Magdalena ideal como una "fortaleza": "La violencia se está instalando y Magdalena precisa entender que tiene una configuración geográfica extremadamente ventajosa. Nos podemos aislar como una fortaleza".

Otra habitante del complejo coloca en la realización del muro el símbolo de una acción colectiva, de buena vecindad.

El Muro no es sólo un 'muro' que divide Magdalena con el límite de otras localidades vecinas. Este muro tiene muchos significados. Es el puntapié incial para medidas más extremas de seguridad, como vigilancia, ciclovías y la tan soñada práctica de la buena vecindad.

En julio comenzó la construcción y con ella los problemas. Se paralizó la colecta a medio camino: "Somos más de 200 casas y apenas 41 pagaron...". Por otro lado, se constató que la construcción no impedía el paso. Irónicamente, se convirtió en un lugar de reunión y desde Vila Argento continuaban cruzando al lago. El muro requirió de sucesivas reformas para mejorarlo, que tampoco lograron el objetivo deseado, y en noviembre es quebrado. Aunque se incrementaron las medidas colocando vidrios sobre el muro y arreglando el orificio, "Ios marginales" continuaron entrando, agrandando el agujero. "El agujero en el muro fue cerrado la semana pasada, después el portón fue derrumbado y el agujero reabierto por los marginales. Esta semana lo agrandaron. Estamos en guerra". Aún hoy es frecuente ver grupos de adolescentes o familias bañándose en el lago, aunque el muro continúa erguido.

Desde un punto de vista legal, el acceso al lago no puede ser cortado por unos vecinos a otros ${ }^{9}$. ¿Dónde descansa la legitimidad de la decisión, el fundamento de la autoridad? En particular, en Magdalena, un caso llevado al límite, el espacio que fundamenta la autoridad se trata de un chat, un foro de debate virtual, donde participan centralmente 12 personas, aunque lo reciben 180 direcciones. Desde allí se convoca a

\footnotetext{
${ }^{9}$ El trámite legal para conformar un condominio cerrado en Brasil es complicado, caro y requeriría además en este caso solucionar la abultada deuda del conjunto con sus guardas.
} 
asambleas y solo una de ellas supera la docena de personas. Pero se arrogan el derecho y no son impugnados.

En su trabajo Fuerza de ley, que recoge conferencias dictadas en Estados Unidos, Derrida (2008) presenta algunos ejemplos de aporías entre derecho y justicia, y de ello obtenemos una primera pista en la dirección de la justicia: hay un límite que se traspasa cuando el fundamento de la autoridad se muestra como un producto descarnado del diferencial de fuerza.

\begin{abstract}
"Se trata siempre de la fuerza diferencial, de la diferencia como diferencia de fuerza, de la fuerza como diferenzia, o fuerza de diferenzia (la diferenzia es fuerza diferida/difiriente); se trata siempre de la relación entre la fuerza y la forma, entre la fuerza y la significación; se trata siempre de fuerza 'performativa', fuerza ilocucionaria y perlocucionaria, de fuerza persuasiva y de retórica" (ibídem: 19-20).
\end{abstract}

\title{
3.2. El portón de Valderas
}

A medida que la zona crecía en población, el pasaje que comunica Valderas y Calle 7, que funcionaba como salida al descampado, comenzó a ser transitado en sentido inverso: "Cuando los policías los seguían se metían por el pasaje. No caben los autos, entonces pasaban y terminaban acá con las cosas robadas, robaban acá y se las llevaban por ahi". Los vecinos de Valderas consideran ese pasaje el principal foco de inseguridad: "Ahí había muchachotes tomando vino y lío todas las noches. No podías salir de tu casa", conversan en el grupo de discusión; "De un lado están ellos y del otro lado estamos nosotros".

Organizados en una comisión vecinal, decidieron primero establecer un patrullaje en grupos, todas las noches. Se desgastaron, cansados, y decidieron contratar un guardia privado, pero el guardia resultó insuficiente y se construyeron unos portones que cerraron el pasaje: "estaba el pobre hombre allá arriba y acá abajo... Entonces, teniendo la pasada cerrada, era más fácil, poniendo los portones".

Desde su punto de vista es una protección justa. Los portones los cierra a las 22.00 y los vuelve a abrir a las 7.00 un vecino de Calle 7 , que vive en el terreno lindero y a quien la asociación de Valderas paga informalmente para que cumpla esta función. Defienden que así focalizaron en una zona claramente conflictiva y que está dando resultados: "Valderas ahora está tranquilo. Hace tiempo que no roban ni 
casas ni nada". Su intención es despiadadamente buena: "purificar ese espacio, limpiarlo, transformarlo, hermosearlo, por decirlo de alguna forma".

La llegada a Calle 7 del programa de regulación de vivienda PIAI (Programa de Integración de Asentamientos Irregulares), un plan de erradicación de los asentamientos irregulares llevado adelante por la IM, detectó la división existente y propuso transformar el espacio abriendo vías para la integración entre los vecindarios, lo que generó fuertes resistencias en Valderas: "¿Cómo me pueden venir a hacer una integración con ese tipo de gente? Cómo yo me puedo integrar a esos botijas que la han pasado mal, que no han tenido padres... un montón de carencias. Porque no hay forma. Yo no creo que a esa gente la puedas recuperar", se expresa en una de las intervenciones más descarnadas en los grupos de discusión.

Pese a sus objeciones, se están dando los primeros pasos en un proceso que se prolongará por años, en el cual se abrirá una avenida, se realizarán algunas expropiaciones y construcciones y se regularizará la situación habitacional de Calle 7 . Se avecina inexorable un cambio. Los integrantes de la comisión barrial de Valderas tuvieron reuniones con los trabajadores sociales que implementan la primera etapa del PIAI y que buscaban "construir un consenso". No tienen derecho legal para administrar el pasaje, pero consideran su decisión justa y así apelarán al concejo municipal, difundirán el caso públicamente ${ }^{10}$, ya que buscan una excepción. Apuntan que "cada caso es otro, cada decisión diferente y requiere una interpretación absolutamente única que ninguna regla existente y codificada podría ni debería garantizar absolutamente" (Derrida, 2008: 53).

Aparece nuevamente un diferencial de fuerza: antes la comisión de Valderas y sus delegados municipales atribuyéndose el derecho a poner un límite, luego, el PIAI, que aboga que en Calle 7 la situación es idéntica a la de la zona 3 en WP, donde "había sectores que, a pesar de ser pobres, procuraban llevar una vida ordenada dentro de sus recursos y posibilidades y que convivían con otros vecinos cuya vida doméstica

\footnotetext{
${ }^{10}$ Con consecuencias indeseadas: la difusión del caso se concentrará rápidamente en el descubrimiento por los periodistas de que el guardia, contratado informalmente, portaba un arma. Las figuras liminales: los guardias contratados irregularmente y con una deuda impaga en Magdalena, los operarios del portón, vecinos de Calle 7, el guardia en Valderas, suelen pagar el precio de la situación.
} 
estaba más desorganizada" (Elias y Scotson, 2000: 146) ${ }^{11}$. Se trata de una situación donde es difícil discernir. Podría parecer inapelable el punto de vista de los técnicos del PIAI, que al fin y al cabo fundan su fuerza de ley en la ejecución de políticas municipales. Sin embargo, el plan de erradicación de asentamientos es una política regional desarrollada por el Banco Interamericano de Desarrollo (BID), un organismo multilateral, que establece las pautas de intervención para otorgar el financiamiento económico: la apertura de avenidas, la realización de censos y realojos, y que se desarrolla en forma idéntica en las periferias de numerosas ciudades del continente, como Manaos o Montevideo. El programa es un estándar para América Latina, elaborado por un banco. Llevada al límite, la situación parece indecidible (Derrida, 2008: 57), con víctimas enfrentadas entre sí en contextos de fuerte exclusión.

"Uno dice que la esencia de la justicia es la autoridad del legislador; otro, la conveniencia del soberano, otro, la costumbre presente; y es esto lo más seguro: nada, siguiendo la sola razón, es justo por sí mismo: todo vacila con el tiempo (...) es el fundamento místico de la autoridad. Quien la devuelve a su principio la aniquila." (Blaise Pascal, Pensées, § 294, edición Brunschvicg, apud Derrida, 2008: 28-29 ${ }^{12}$ ).

\subsection{En el límite, la hospitalidad}

En los tres casos se presenta el mismo entretejido, más allá de los contenidos concretos. Se pone en juego una configuración microsociológica pautada por cuatro engranajes fundamentales: el carácter diferencialmente distribuido de la cohesión interna y de los espacios de poder; identificaciones cruzadas que amplifican casos extremos; historias, anécdotas y rumores elogiosos o degradantes;

\footnotetext{
${ }^{11}$ La cita continúa y merece la pena reseñarla: "Las relaciones tensas, como las que existían entre las familias trabajadoras de la aldea y la mayoría de las familias trabajadoras del loteamiento, por una parte, y la minoría de familias trabajadoras de mala fama, por otro, no constituyen un caso aislado, ni siquiera en nuestra época. (...) Si consideramos desarrollos de más largo plazo, es probable que se constate que parte de las familias proletarias desestructuradas, las familias problema de hoy, constituyen el remanente progresivamente menor de generaciones enteras de familias de ese tipo (...) que no consiguen escapar del círculo vicioso que tiende a producir, en los hijos de las familias mal estructuradas, una propensión a formar, en su generación, familias mal estructuradas" (ibídem: 146-147).

${ }^{12}$ Blaise Pascal, como señala Derrida en una bella metáfora de esta diluyente referencia al origen de la autoridad, parafrasea sin citar a Montaigne, Essais, III, cap. XIII, "De l'expérience", Bibliothèque de la Pléiade, p. 1203. (Cf. la trad. esp. de Dolores Picazo y Almudena Montojo, Ensayos, III, p. 346, Cátedra, Madrid, 1987).
} 
focalización en algunos jóvenes "anómicos". La mayor homogeneidad y organización de los establecidos, que se identifican a si mismos con su minoría más próspera, se opone a los outsiders, llegados luego y marginales caracterizándolos como a su minoría peor, generalizando algunos rasgos en forma infundada. Los primeros se sienten víctimas en el cambio de las cosas - antes estaban mejor-y establecen una fuerza performativa, retórica y perlocucionaria que impone un límite. De su lado, muestran sus anécdotas y toman medidas.

¿Qué hay del otro lado, fuera del borde, para mostrar? Más bien poco, están desorganizados y son heterogéneos: cuando toman la palabra dicen que también están fatigados, que son algunas personas las que provocan los problemas, más agudos aun en su propio barrio, a las numerosas familias de bien; quieren integrarse, se oponen a ese límite y lo consideran injusto. Por su parte, los unánimemente señalados como culpables, los "jóvenes anómicos" también arguyen ser víctimas cuando se les pregunta.

Todos los participantes se dicen entonces víctimas, cada una ocupando un lugar distinto con sentidos diferentes, antagónicos. De un lado, los establecidos se sienten invadidos y su respuesta es mantener distancia respecto a esas figuras amenazantes. De otra parte, a la mayoría de los situados fuera por los establecidos, les molesta ser tratados de igual forma que otros "realmente hostiles" a los que se refieren muchas veces con particular crudeza porque están cercanos y los afectan. En tercer término, los unánimemente apuntados como amenazantes, jóvenes problemáticos, llaman "asociales" a los que no se acercan a comprender. Son situaciones indecidibles, en tanto emergen pretensiones de justicia encontradas en una espiral de hostilidad: los dueños de casa se sienten desafiados por quienes vienen de fuera, que son para ellos extranjeros y enemigos (hostis), disponen un límite, reglas para la recepción, se posicionan como anfitriones (hospes) hostigados y en este proceso se generan rehenes (hostages) y nuevas víctimas (hostias).

El antónimo de la hostilidad es la hospitalidad. Como juego opuesto a la hostilidad, "la hospitalidad se presenta como un puente frágil y peligroso establecido ente dos mundos: el afuera y el adentro" (Montadon, 2011: 
45) ${ }^{13}$. La respuesta de Elias es hospitalaria, lo que no deja de ser arriesgado:

"La hospitalidad absoluta puede también abrir siempre un espacio salvaje de violencia. No debemos ignorar ese riesgo, ni desdeñar a los que quieren establecer barreras o parapetos del derecho contra esa locura de la hospitalidad absoluta. Pero no debemos dejar de intentar pensar y vivir la posibilidad de la inversión, por tanto de la perversión, que debe quedar abierta para que una hospitalidad sea posible." (Michaud, 2011: 1001).

Esto sitúa la responsabilidad o más bien la posibilidad de una solución del lado de los establecidos, los que reciben. Por dos motivos. Ellos también se dicen víctimas, pero tienen el lugar dominante, que da sentido al espacio; proponen el idioma que se exige hablar pero que el extranjero no logra sino articular penosamente, siempre más o menos separado de los dueños del espacio, del anfitrión. Son los únicos que pueden dar la palabra, recibir al otro, acusarlo con cierta razón de falta de códigos, quienes pueden dejar entrar.

Por otra parte, además, la situación tiene resultados diferenciales sobre los jugadores. Los rehenes son los más afectados; reciben hostilidad tanto de establecidos como de "jóvenes problemáticos", y solo la ejercen hacia uno de ellos, estos últimos. En segundo lugar, los unánimemente señalados como problemáticos reciben segregación de las otras dos posiciones y hostigan a ambas. En tercer lugar, los establecidos, como única víctima con saldo positivo, son hostigados por algunos jóvenes, pero los segregan a ellos y a los rehenes. Así, la hospitalidad lleva la política a cierto lugar: en el origen de la familia hospes, hostis, hostage, se encuentra el verbo hostire, igualar, tratar de igual a igual, romper el límite.

\footnotetext{
${ }^{13}$ La noción adquiere estatus, por así decirle, trascendente a raíz de la reflexión de Immanuel Kant (2005), en dos trabajos centrales en su filosofía política ("Ideas para una historia universal en clave cosmopolita" y "Sobre la paz perpetua"). De cualquier modo, es con Emmanuel Levinas cuando "se atribuye a la hospitalidad el papel de concepto operatorio nuevo y único en la filosofía europea moderna" (Manzi y Toudoire, 2011: 1160). La noción de hospitalidad se encuentra en el centro de su reflexión filosófica, donde la ética, en lo que tiene de ethos, remite a la hospitalidad desde su etimología: la habitación, la propia casa (Montadon, 2011: 997). La hospitalidad absoluta o incondicional en el sentido de Levinas, "supone una ruptura con la hospitalidad en el sentido corriente, con la hospitalidad condicional, con el derecho o pacto de hospitalidad" (apud Montadon, 2011: 59). En otra línea de análisis similar, con énfasis kantiano, Seyla Benhabib (2004) introduce la noción de "iteraciones democráticas".
} 
El suplemento del muro en Magdalena y el portón en Valderas establecer el límite- muestra la entrada en escena de una decisión que radicaliza la configuración de Elias y Scotson (2000), donde una de las partes, que se considera legítima, toma medidas en estas situaciones indecidibles apoyada en el diferencial de fuerza y en una autoridad cuyo fundamento se revela siempre impugnable. Se establece entonces un cierto tipo de diferencia hostil que Jean-François Lyotard denomina diferendo: "Un diferendo se produce cuando el 'reglamento' del conflicto que los opone se desarrolla en el idioma de una de las partes, en tanto que la sinrazón de que sufre la otra no se significa en ese idioma" (1999: 12). Y como la solución lo es solo para una de las partes, la otra se vuelve una víctima, ahora en el sentido de Lyotard, aquella posición que queda sin palabras luego de la decisión: "Hay un silencio encerrado en la estructura violenta del acto fundador. He ahí el sentido de lo que yo me atrevería a interpretar de lo que Montaigne y Pascal llaman el fundamento mistico de la autoridad" (Derrida, 2008: 33, cursiva en el original).

La configuración que proponen Elias y Scotson (ibídem) entre establecidos y outsiders o marginales se demuestra vigente: el conjunto de engranajes permite el análisis y la descripción de casos actuales. Asimismo, la pregunta que subyace en su texto acerca de la justicia en esas situaciones es evidentemente relevante en la actualidad, donde los muros, las migraciones, las extranjerías son cada vez más frecuentes. Su respuesta, apuntando a la hospitalidad y a la comprensión, se encuentra en la línea de la reflexión eticopolítica sobre este tema de varios autores (Benhabib, 2004; Derrida, 1997; Montadon, 2011). Llevar al límite la configuración, tomar la decisión de limitar, solo incrementa la injusticia y genera nuevas víctimas.

\section{BiBLIOGRAFÍA}

Allport, G. (1962). La Naturaleza del Prejuicio. Buenos Aires: Eudeba.

Álvarez-Rivadulla, M. J. (2017). The Weakness of Symbolic Boundaries: Handling Exclusion Among Montevideo's Squatters. International Journal of Urban and Regional Research, 41(2), 251-265

Barth, F. (1976). Los grupos étnicos y sus fronteras. La organización social de las diferencias culturales. Ciudad de México: FCE. 
Benhabib, S. (2004). Los derechos de los otros. Extranjeros, residentes y ciudadanos. Barcelona: Gedisa.

Derrida, J. (1997). El monolingüismo del otro o la prótesis del origen. Buenos Aires: Manantial.

Derrida, J. (2008). Fuerza de Ley. El fundamento mistico de la autoridad. Madrid: Tecnos.

Elias, N. (1989). El proceso de la civilización. Ciudad de México: FCE.

Elias, N. (1998). La sociedad de los padres y otros ensayos. Bogotá: Norma.

Elias, N. (2003). Ensayo acerca de las relaciones entre establecidos y forasteros. Revista Española de Investigaciones Sociológicas, 104(OctDec), 219-251.

Elias, N., y Scotson, J. (2000). Os Establecidos e os outsiders. Río de Janeiro: Jorge Zahar.

Elias, N., y Scotson, J. (2016). Establecidos y marginados. Una investigación sociológica sobre problemas comunitarios. Ciudad de México: FCE.

Elster, J. (1999). Alchemies of the Mind: Rationality and the Emotions. Cambridge: Cambridge University Press.

Elster, J. (2005). En favor de los mecanismos. Revista de Sociología, 19(57), 239-273

Goffman, E. (1989). La presentación de la persona en la vida cotidiana. Buenos Aires: Amorrortu.

Kant, I. (2005). Ensayos sobre la paz, el progreso y el ideal cosmopolita. Madrid: Cátedra.

Lamont, M., y Fournier, M. (Eds.) (1992). Cultivating differences: symbolic boundaries and the making of inequality. Chicago: University of Chicago Press.

Luhmann, N. (1998). Sistemas sociales: lineamientos para una teoría general. Barcelona: Anthropos.

Lyotard, J. F. (1999). La diferencia. Barcelona: Gedisa.

Manzi, J., y Toudoire, F. (2011). O estrangeiro. O desconhecido que bate a minha porta. En A. Montadon (Ed.), Hospitalidade. Acolhida do extrangeiro na história e nas culturas (pp. 795-804). San Pablo: Senac.

Merton, R. (2003). Teoría y estructuras sociales. Ciudad de México: FCE.

Michaud, G. (2011). Jaques Derrida. Um pensamento do incondicional. En A. Montadon (Ed.) Hospitalidade. Acolhida do extrangeiro na história e nas culturas (pp. 1001-1011). San Pablo: Senac. 
Montadon, A. (Ed.) (2011). Hospitalidade. Acolhida do extrangeiro na história e nas culturas. San Pablo: Senac.

Simmel, G. (2005). La metrópolis y la vida mental. Bifurcaciones, 4(primavera). Recuperado

de: www.bifurcaciones.cl/004/reserva.htm.

Weber, M. (2004). La ética protestante y el espíritu del capitalismo. Madrid: Alianza. 